\title{
Syntactic categories informing variationist analysis: The case of English copy-raising
}

\author{
Marisa Brook ${ }^{*}$
}

\author{
LSA Annual Meeting, Portland, OR, January 8-11, 2015
}

1. Introduction. English has a small set of verbs - seem, appear, look, sound, and feel - that denote the ostensible nature of a proposition within a subsequent finite subordinate clause. These verbs are linked to the embedded clause by one of five "comparative complementizers" (Rooryck 2000:48, López-Couso \& Méndez-Naya 2012a:172): as if, as though, like, that, and Ø:

(1) It seems (as if/as though/like/that/Ø) it's going to rain today.

Not all twenty-five possible combinations of verb and complementizer are grammatical (Potsdam \& Runner 2001:465, Gisborne 2010:275, Huddleston \& Pullum 2002:962; Brook 2014:4); however, there is enough variation between the complementizers in the contexts of these verbs to have justified variationist studies of their patterning (López-Couso \& MéndezNaya 2012a, 2012b). My earlier study, using the Toronto English Archive (TEA) (Tagliamonte 2003-2006; Tagliamonte 2006) found that like is the incoming variant in apparent time in Toronto (Brook 2014:4). As if and as though are negligible in this context in the corpus (LópezCouso \& Méndez-Naya 2012a:185); that and $\varnothing$ are low-frequency and in decline (Brook 2014:4).

One aspect of the results that I left largely unexplained was that younger speakers in Toronto were using the (ostensibility verb) + (comparative complementizer) structure more than older speakers overall. This finding was incidental, but establishes the focus of the present study. Neither of the potential explanations that I have previously considered (Brook 2014:4-5) has a sufficient explanatory power to account for the results. In the present paper, I consider a new possibility: that the entire (ostensibility verb) + (comparative complementizer) structure is undergoing a trade-off in apparent time with the related syntactic construction of Subject-toSubject raising.

2. Background. The variation being explored is centred around a syntactic transformation known as copy-raising or 'Richard' (Rogers 1974, Postal 1974). This has conventionally though not invariably (Gisborne 2010) - been analyzed as the embedded subject raising to the matrix subject position and leaving behind a coreferential pronoun:

(2a) It seemed like Sheila was looking for something.

(2b) Sheila $a_{i}$ seemed like she $_{\mathrm{i}}$ was looking for something.

Two subsets of the TEA data do not involve copy-raising at all. First, feel is not typically used as a copy-raising verb (The chair feels like it's about to catch on fire); far more often it simply has an experiencer matrix subject (I feel like this is weird), and thus will be left out of the analysis. Second, copy-raising does not occur with the complementizers that and $\emptyset$ (Potsdam \& Runner 2001:465, Gisborne 2010:275). Therefore, even excluding feel, there is still a mix of syntactic

\footnotetext{
* I am indebted to Sali A. Tagliamonte, Diane Massam, J. K. Chambers, Derek Denis, Bronwyn Bjorkman, Matt Hunt Gardner, Bridget Jankowski, Aaron Dinkin, Alexandra D’Arcy, Ruth Maddeaux, Shayna Gardiner, Emily Blamire, and Naomi Nagy for their comments, guidance, and suggestions. I would also like to thank the University of Toronto Language Variation and Change group, the research assistants who collected and transcribed the data, and my audience at LSA. Author: Marisa Brook, University of Toronto (marisa.brook@ mail.utoronto.ca).
} 
environments in the data: those where copy-raising is forbidden, where it is permitted but not realized (as in 2a), and where it is realized (as in $2 b$ ). These will be untangled below.

Copy-raising is closely related to Subject-to-Subject raising (Rosenbaum 1967; see also López-Couso \& Méndez-Naya 2012b:325) - so closely that Subject-to-Subject raising may play a role in change involving copy-raising (see e.g. Hopper \& Traugott 2003:175). This is the hypothesis evaluated here.

3. Methodology. The objective is to examine the possibility of change between copy-raising and Subject-to-Subject raising. However, even including feel, there are very few examples $(\mathrm{N}=4)$ of Subject-to-Subject raising with any of the verbs other than seem $(\mathrm{N}=248)$. Therefore, the present analysis is limited to finite and non-finite tokens of seem.

The extraction and coding of the finite tokens of seem follow Brook (2014) but include negative-polarity contexts, since matrix negation in the context of copy-raising verbs is semantically attached to the embedded clause ("transferred negation", Quirk et al. 1985:10331034; see also Gisborne 2010:278). In other words, there is no reason to distinguish It doesn't seem like it's going to rain from It seems like it's not going to rain.

The possibility of raising being implicated in change means having to define complex syntactic constructions as co-variants - and on a level broader than that of the complementizers alone. One such variant is raising, i.e. the non-finite tokens. How to split up all of the finite ones - blocked, permitted, and realized copy-raising - is an empirical question for the next section.

4. Results and discussion. The first step was to establish whether the finite tokens show a relationship in apparent time with the non-finite tokens in the TEA. Figure 2 demonstrates that they do: the raising tokens are losing ground in apparent time to the finite ones.

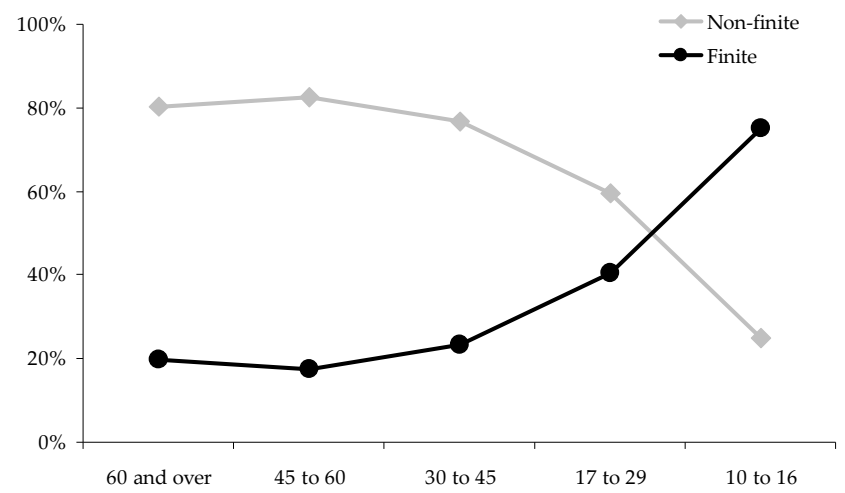

Figure 1: Finite and non-finite tokens of seem in the TEA in apparent time $(\mathrm{N}=369)$.

At this point, there is already a tidy explanation for why younger people are using more comparative complementizers in Toronto: it is because this is only half of a change. Copy-raising with seem is overtaking Subject-to-Subject raising with seem. The raising tokens provide the other part of the picture.

The finite tokens (copy-raising blocked/permitted/realized) are still grouped together, with the question of how best to split them up remaining. Variationist methodology makes it straightforward to test competing claims, so two approaches will be considered. The first is to divide up the finite tokens according to which complementizers vary with each other where: this is shown in Table 1. In this case, one construction variant would be where all five comparative complementizers are allowed, and the other would be where only a subset of them are. 


\begin{tabular}{lll}
$\begin{array}{l}\text { Variation1 } \\
\text { Expletive subjects }\end{array}$ & $\begin{array}{l}\text { Variation2 } \\
\text { Raising }\end{array}$ & $\begin{array}{l}\text { Variation3 } \\
\text { Referential subjects }\end{array}$ \\
\hline $\begin{array}{l}\text { it seems as if/as } \\
\text { though/like/that/Ø }\end{array}$ & NP seems to & $\begin{array}{l}\text { NP seems as if/as } \\
\text { though/like }\end{array}$ \\
\hline
\end{tabular}

Table 1: Division of seem tokens into three categories according to variable context.

An alternative approach would be to follow a theoretical distinction. This is equivalent to a surface-level idea of where the complementizers appear. Table 2 shows this division:

\begin{tabular}{lll}
$\begin{array}{l}\text { Syntax1 } \\
\text { Copy-raising blocked }\end{array}$ & $\begin{array}{l}\text { Syntax2 } \\
\text { Raising }\end{array}$ & $\begin{array}{l}\text { Syntax3 } \\
\text { Copy-raising permitted }\end{array}$ \\
\hline & & $\begin{array}{l}\text { it seems } \text { as if/as } \\
\text { though/like }\end{array}$ \\
it seems that/ $\varnothing$ & NP seems to & $\begin{array}{l}\text { NP seems as if/as } \\
\text { though/like }\end{array}$ \\
& &
\end{tabular}

Table 2: Division of seem tokens into three categories according to syntactic properties.
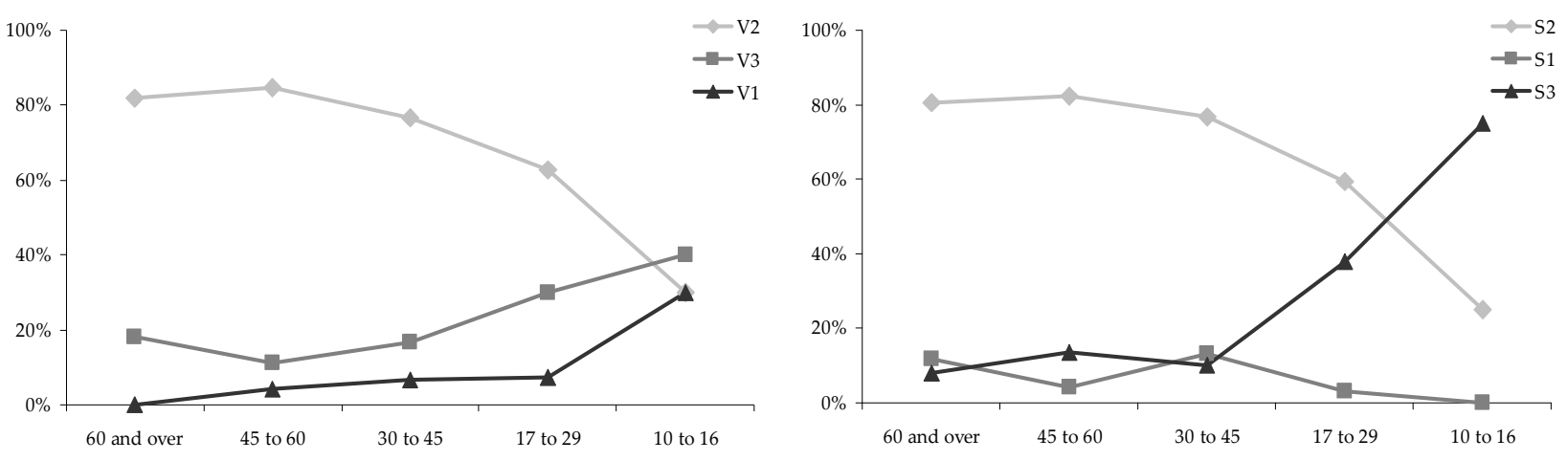

Figure 2: Split of finite tokens according to variation (left) and by syntactic properties (right).

The results are shown in Figure 2. The syntactic division is the more informative result: it identifies a single innovative variant (Syntax3) taking over from the non-finite (raising) tokens (Syntax2). The change leading to the loss of seem $*$ to can be squarely attributed to a single syntactic class: the context (Syntax3) in which copy-raising is possible (though not necessarily realized). The tokens of blocked copy-raising (Syntax 1) - it seems that and it seems $\emptyset$ - are infrequent to begin with and are being lost along with the raising.

One additional prediction falls out of the division by syntactic properties. In this model, seem* like is competing directly with seem* as if and seem* as though, but seem* that and seem* $\varnothing$ are buffered somewhat by being two steps away. With like as the incoming complementizer, this suggests that like should be able to overtake as if and as though more readily than that and $\varnothing$. Such an asymmetry is precisely what I have observed (Brook 2014:4).

Two types of morphosyntactic change are progressing simultaneously in Toronto. Younger speakers are more likely to say both It/he seems like he's sick rather than other complementizers, and It/he seems like he's sick (type Syntax3) rather than He seems to be sick (type Syntax 2). A fixed-effects logistic regression using Goldvarb X (Sankoff et al. 2005) confirms significant ( $\mathrm{p}<$ 0.05) effects of age (young people favouring Syntax3) and gender (women favouring Syntax3), exactly as would be predicted for a change-in-progress (see e.g. Labov 2001:501). 
5. Conclusion. A combination of syntactic theory and variationist methods has uncovered a well-behaved change-in-progress operating on a broader level from most morphosyntactic variables. Testing competing theories is a key capability of variationist methods; tailoring the analysis to best fit the linguistic facts is what allows the variationist approach to succeed. The only concession to syntax was the need to define the constructions according to their syntactic properties - which is not unreasonable for variants that are entire constructions.

The present results do not nullify any earlier findings about inter-complementizer variation; they essentially identify these as subcomponents of a larger change, with that and $\varnothing$ separated from as if, as though, and like by the intermediary that is Subject-to-Subject raising.

These results reaffirm the value of looking past the traditional variable context (Aaron 2010) to investigate whether related and/or overlapping syntactic structures might be crucially implicated in a change. The notion of orderly heterogeneity (Weinreich et al. 1968:100-101) has shown itself to be able to apply to straightforward categories of generative grammar as they are employed in vernacular speech. In this case, I have shown that there is a place for abstract syntactic categories in the quantitative realm of variationist sociolinguistics - and vice versa.

\section{References}

Aaron, Jessi Elana. 2010. Pushing the envelope: Looking beyond the variable context. Language Variation and Change, $221,1-36$.

Brook, Marisa. 2014. Comparative complementizers in Canadian English: Insights from early fiction. University of Pennsylvania Working Papers in Linguistics 20(2). 1-10. http://repository.upenn.edu/pwpl/vol20/iss2/

Gisborne, Nikolas. 2010. The event structure of perception verbs. Oxford: Oxford University Press.

Hopper, Paul J. \& Elizabeth Closs Traugott. 2003. Grammaticalization (2 ${ }^{\text {nd }}$ ed.). Cambridge: Cambridge University Press.

Huddleston, Rodney \& Geoffrey K. Pullum (eds). 2002. The Cambridge grammar of the English language. Cambridge: Cambridge University Press.

Labov, William. 2001. Principles of linguistic change, volume 2: Social factors. Malden, MA: Blackwell.

López-Couso, María José \& Belén Méndez-Naya. 2012a. On the use of as if, as though, and like in present-day English complementation structures. Journal of English Linguistics 40(2). 172-195.

López-Couso, María José \& Belén Méndez-Naya. 2012b. On comparative complementizers in English: Evidence from historical corpora. In Nila Vázquez (ed.), Creation and use of historical English corpora in Spain. 311333. Newcastle-upon-Tyne, UK: Cambridge Scholars Publishing.

Postal, Paul. 1974. On raising. Cambridge, MA: MIT Press.

Potsdam, Eric \& Jeffrey T. Runner. 2001. Richard returns: Copy raising and its implications. In Mary Andronis, Chris Ball, Heidi Elston \& Sylvain Neuvel (eds.), CLS 37: The main session, volume 1. 453-468. Chicago: Chicago Linguistic Society.

Quirk, Randolph, Sidney Greenbaum, Geoffrey Leech \& Jan Svartvik. 1985. A comprehensive grammar of the English language. Harlow, UK: Pearson Education.

Rogers, Andrew D. 1974. Physical perception verbs in English: A study in lexical relatedness. Los Angeles, CA: University of California dissertation.

Rooryck, Johan. 2000. Configurations of sentential complementation: Perspectives from Romance languages. London: Routledge.

Rosenbaum, Peter S. 1967. The grammar of English predicate complement constructions. Cambridge: MIT Press.

Sankoff, David, Sali A. Tagliamonte, \& Eric Smith. 2010. Goldvarb X (software). Department of Linguistics, University of Toronto. http://individual.utoronto.ca/tagliamonte/goldvarb/

Tagliamonte, Sali A. 2003-2006. Linguistic changes in Canada entering the 21st century. Research grant, Social Sciences and Humanities Research Council of Canada (SSHRCC). \#410-2003-0005.

Tagliamonte, Sali A. 2006. "So cool, right?": Canadian English entering the $21^{\text {st }}$ century. Canadian Journal of Linguistics 51(2/3). 309-331.

Weinreich, Uriel, William Labov \& Marvin Herzog. 1968. Empirical foundations for a theory of language change. In Winfred P. Lehmann \& Yakov Malkiel (eds.), Directions for historical linguistics. 95-188. Austin, TX: University of Texas Press. 